\title{
CARACTERIZAÇÃO MICROESTRUTURAL E MECÂNICA DE JUNTA SOLDADA EM AÇO MÉDIO CARBONO E BAIXA LIGA
}

\section{Fabiano Silva Assunção' \\ Juliene Ozorio Lacorte ${ }^{2}$ \\ Maria Cristina Carrupt Ferreira Borges ${ }^{3}$}

Resumo: Os aços $A R B L$, considerados de alta resistência e baixa liga, são largamente empregados na indústria aeronáutica e automobilística. Na indústria aeronáutica, são utilizados em partes do trem de pouso e na fabricação do "berço-de-motor" de aeronaves de pequeno porte. Essa estrutura é um componente submetido a carregamentos complexos, cujas fraturas ocasionadas por fadiga são constantes. São construídos com chapas de espessura de $1.10 \mathrm{~mm}$ e soldados pelo processo GTAW (TIG). Esse trabalho tem como objetivo identificar as fases presentes na microestrutura da junta soldada em aço ABNT 4130, destinadas à fabricação do "berço-de-motor", e suas características mecânicas. Foi realizado ensaio de tração, microscopia ótica e microscopia eletrônica de varredura (MEV). Os resultados obtidos mostram a formação de fases frágeis e uma considerável alteração nas propriedades mecânicas da junta soldada, em relação ao material.

Palavras-chave: Aço SAE 4130; Soldagem GTAW; Microestruturas; Propriedade Mecânica.

\footnotetext{
1 Tecnologia Mecânica assuncao.fsa@hotmail.com.

2 Tecnologia Mecânica julienelacorte@gmail.com.

3 Tecnologia Mecânica maria.b@fatec.sp.gov.br.

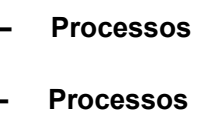

